\title{
Учебный центр «Школа профессионалов аналитики" раскрывает секреты
}

Рассказывают председатель совета директоров компании "Хромос Инжиниринг" Андрей Львович Пахомов и технический директор центра Егор Александрович Чудин

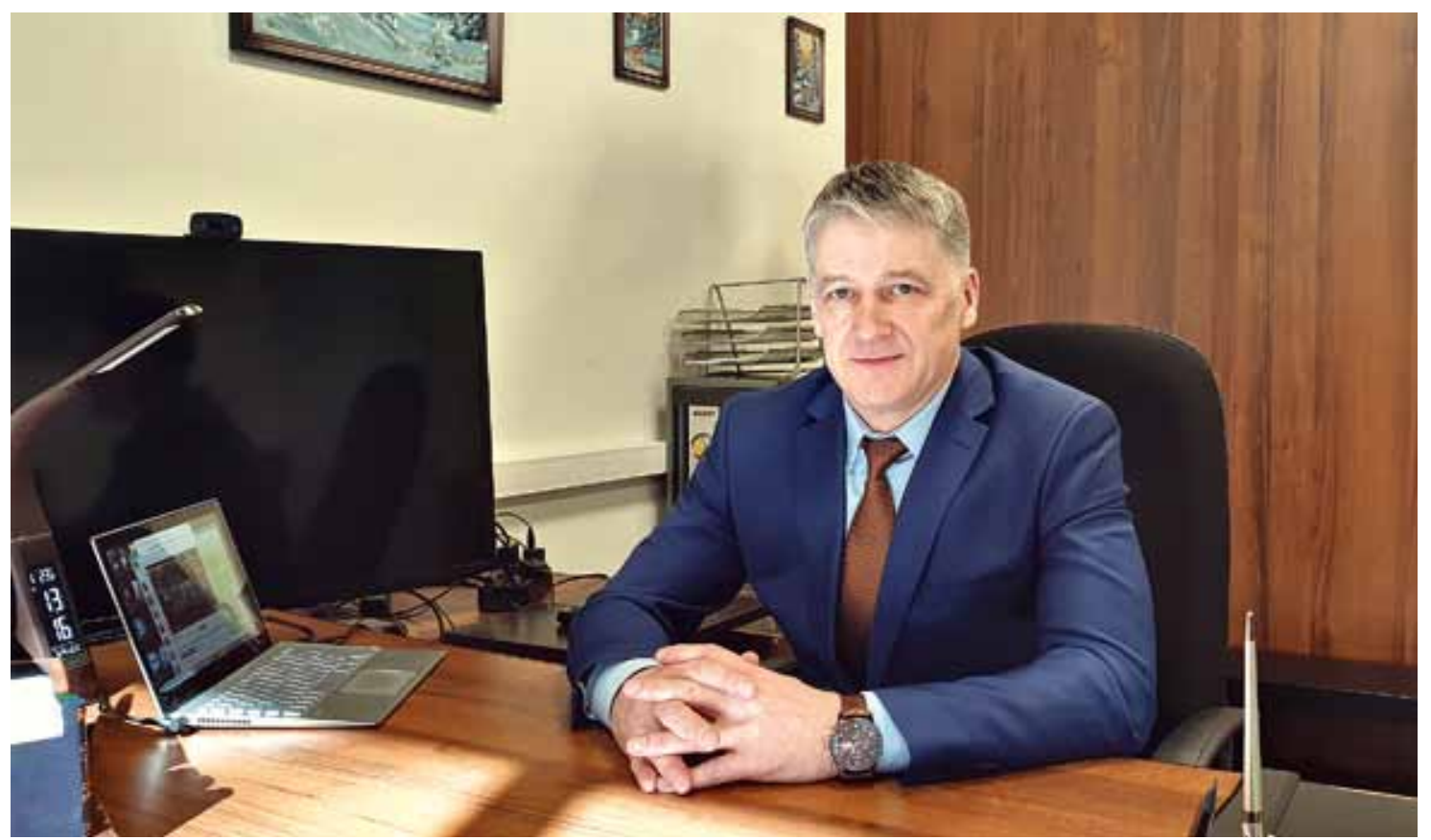

Компания "Хромос Инжиниринг», один из лидеров российского рынка по производству и продаже лабораторных и промышленных хроматографов, уделяет пристальное внимание повышению профессионального уровня отечественных специалистов и улучшению качества продукции российских производителей, а также совершенствованию системы нормативной документации и контроля качества. Опираясь на собственный, более чем 15-летний, опыт, компания предлагает уникальные, не имеющие аналогов разработки оборудования для хроматографии, и новую, революционную модель контроля качества продукции от момента ее закупки до запуска и поддержания в рабочем режиме в течение всего времени эксплуатации.

Для достижения поставленных целей нужны высокопрофессиональные специалисты, владеющие не только принципами работы лабораторных и промышленныххроматографов, но и разбирающиеся во всех нюансах - юридических, экономических, производственных. Подготовкой инженеров нового поколения занимается собственный учебный центр - «Школа профессионалов аналитики" (далее - Школа аналитики), который был открыт в Москве в ноябре 2017 года. Председатель совета директоров компании “Хромос Инжиниринг» Андрей Львович Пахомов и технический директор центра Егор Александрович Чудин познакомили нас с центром, рассказали об особенностях, целях и задачах обучения, а также о планах развития компании и расширения ее деятельности в нормативную сферу. 
Уважаемые Андрей Львович и Егор Александрович, расскажите о вашем Центре. Каковы его цели и задачи? Какой опыт накоплен с момента открытия?

А. Л. Пахомов: Центр "Школа профессионалов аналитики" предназначен для обучения специалистов КИПиА, начальников лабораторий и самих хроматографистов современным теоретическим и практическим знаниям в области хроматографии и лабораторного анализа. Первая школа состоялась в ноябре 2017 года, в конце марта 2019 года закончилась девятая, а следующая, десятая, пройдет 21 по 23 мая. Мы приглашаем всех желающих пройти повышение квалификации в области газовой хроматографии по программе «Газовые хроматографы. Системы пробоотбора". География слушателей очень широкая, есть опыт проведения выездных школ на территории предприятий. Программа включает практическую и аналитическую часть. Каждый специалист получает ответ на интересующие вопросы по методикам работы, технической стороне хроматографии, техническому обслуживанию, поверке ит.д.

На практических занятиях каждому предоставлена возможность своими руками собрать и разобрать хроматограф.

После окончания курса обучающиеся получают сертификаты Школы аналитики.

А какие еще знания и навыки получают в процессе подготовки обучающиеся? И какую роль играет центр в создании имиджа вашей компании?

А. Л. Пахомов: Слушатели учатся правильно составлять технические задания, принимать оборудование даже в автоматическом режиме, устранять фактор субъективности на этих этапах.

Наша компания предлагает новый подход и считает, что настала пора для замены лабораторных промышленными средствами измерений для контроля качества среды без участия человека (исключить субъективный фактор) в режиме мониторинга (непрерывного контроля). За

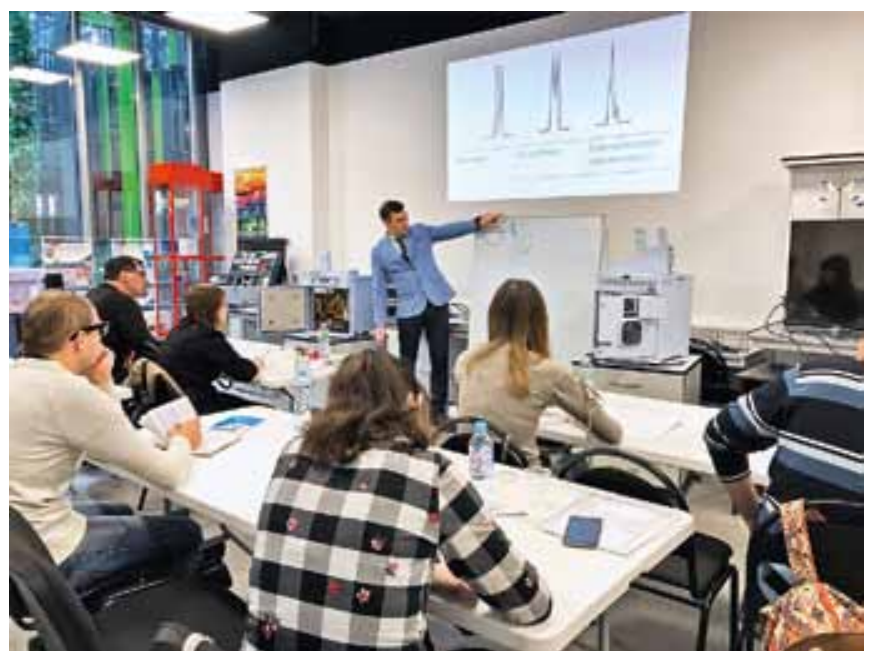

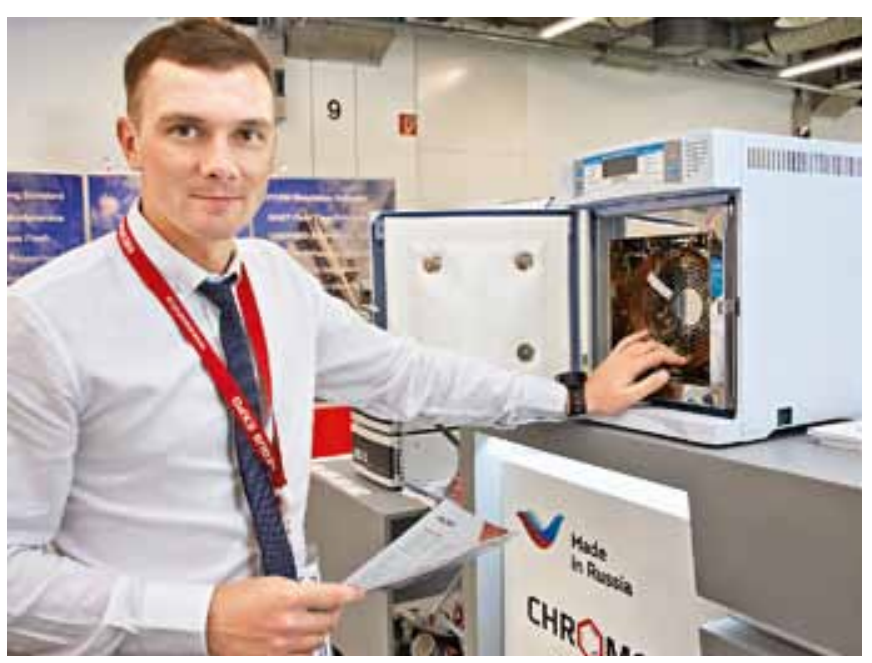

рубежом соотношение потоковых и лабораторных средств измерений составляет 9:1 и все чаще об этом задумываются в России.

Однако у руководителей предприятий остаются вопросы: Как не прогадать с приобретением потоковых средств измерений? Где их размещать? Как будет осуществляться пробоотбор и обеспечиваться достоверность измерений? Насколько дорого обслуживание? и т.д.

На все эти вопросы у нас есть ответы.

Мы разработали предложение о создании пакета документов по приемке оборудования в соответствии с нормативными документами и методиками предприятий.

Мы первые начали проводить мероприятия по валида-

\section{Сервис и обучение можно сделать дистанционными,} подкрепляя это решение

\section{качеством выпускаемого оборудования}

ции оборудования в автоматическом режиме, что позволяет смело продвигать собственную продукцию, предоставляя доступ к ней на всех стадиях работы - от запуска до эксплуатации и консервации, при необходимости. Слушателям мы передаем свой опыт и обучаем юридическим, техническим и финансовым вопросам, связанным с оборудованием и хроматографическими исследованиями для создания на их предприятиях целой базы нормативных документов. А нашу пилотную учебную программу планируем закрепить 
через Минпромторг, что, безусловно, будет способствовать росту качества продукции.

\section{Кто преподает в вашем центре?}

А.л. Пахомов: Самые опытные специалисты.

Анатолий Александрович Миронов, более 50 лет в хроматографии, участвовал в ликвидации и утилизации химического оружия, стоял у основ хроматографии в нашей стране.

Алексей Владимирович Лоскутов, технический специалист, работает с 1993 года.

Егор Александрович Чудин, наш технический директор, имеет большое количество собственных разработок, развивает Школу аналитики, проводит разработки промышленных хроматографов и боксы контроля качества.

\section{При поставке нашей}

\section{продукции клиент}

\section{nолучает за три первых года экспиуатации тройную прибыль}

\section{Как организовано обучение?}

Е. А. Чудин: Стандартный курс повышения квалификации занимает три рабочих дня, оптимальное число слушателей - от 12 до 20. Мы работаем с бюджетными организациями, обучаем их сотрудников, а в дальнейшем поддерживаем с ними связь. Мы учим обнаруживать неисправности и устранять их, отрабатываем базовый набор стандартных ситуаций, наиболее часто встречающихся при реальной

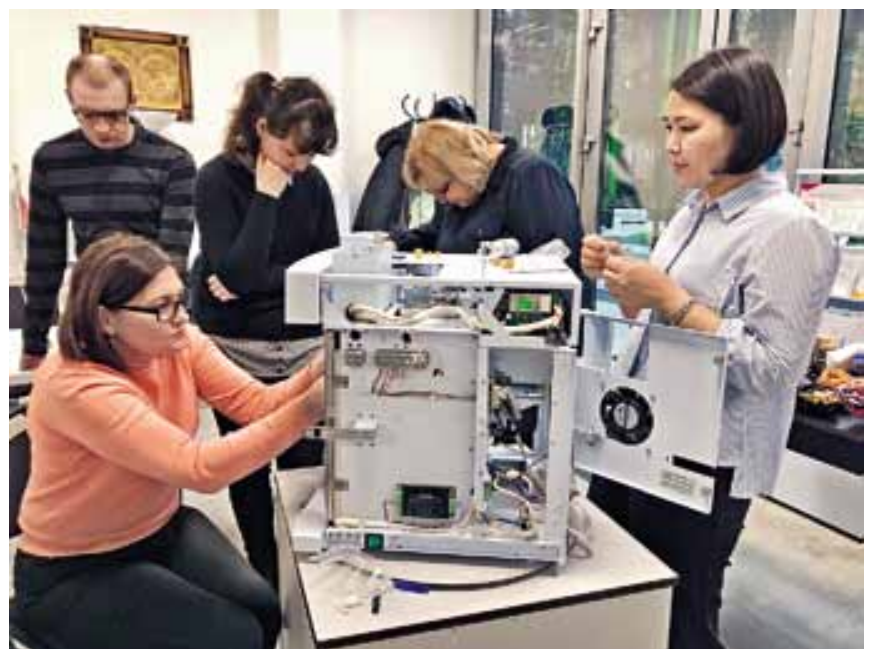

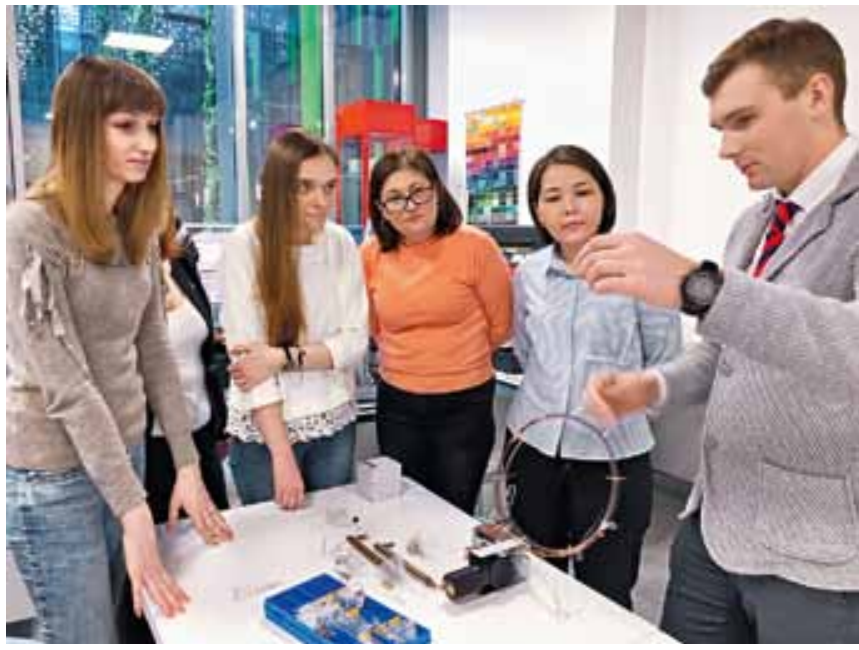

работе с хроматографами. (Отметим, что наши хроматографы не ломались и не требовали ремонта с 2004 года, что подтверждено непрерывными логами их работы). После окончания курса слушатели получают полный пакет учебных материалов в электронном виде, на нашем сайте выложены фото и видео. На время обучения приезжают специалисты, в частности, из Дзержинска, показывают свои презентации, МУКи, затрагиваются такие важные темы, как экология и защита окружающей среды. Мы настаиваем на том, что необходимо проводить валидацию на устройство ввода пробы, а не только на хроматограф, рассказываем о тех аспектах работы, в которых наиболее часто встречаются конфликтные ситуации и потеря качества. Предостерегаем от удаления в ручном режиме данных анализов, полученных с помощью хроматографа, требуем исключить субъективность, "фактор лаборанта", который сейчас встречается повсеместно, говорим о важности сличительных испытаний оборудования на предприятиях и своего, и сторонних производителей. На занятиях приводим статистические данные, полученные на нашем оборудовании при создании ГОСТов в ведущих научных организациях России.

Андрей Львович, вы говорили о высоком качестве продукции вашей компании. В чем ее преимущества и каков ассортимент?

А. Л. Пахомов: Мы создали хроматограф нового поколения, в который включили цифровую шину, работающую по определенному протоколу, что позволяет улучшать электронику прибора, увеличивать ее быстродействие, программно совмещать с новой, усовершенствованной аппаратурой. Глубина совместимости составляет 15 лет, на протяжении которых можно заменять отдельные блоки на более совершенные, модернизированные без привязки к конкретной модели хроматографа прежних лет выпуска. В этом смысле наша линейка хроматографов - единственная в мире. При работе хроматографа 20 точек в секунду пишется лог его работы, от момента первого включения до конца 
эксплуатации. При необходимости лог можно переслать нам, а мы поможем разобраться, в чем причина аварии, сбоя или иной неисправности. Такой подход позволяет выйти на международный рынок, поскольку поддержка работы приборов не зависит от расстояния, а все вопросы можно решить дистанционно. Мы заключили контракт с Саудовской Аравией на пять лет для распространения ими нашего оборудования на территории семи стран, готовимся к подписанию договоров с Венесуэлой. Запустили в серию производство промышленных анализаторов, будем их поставлять в России и за рубеж. Взяли на себя обязательства наладить выпуск хроматографов в объемах 600 шт. в год, разработали модели с низким потреблением энергии, способные работать на солнечных батареях, в проницаемых и непроницаемых оболочках. Мы считаем, что сервис и обучение можно сделать дистанционными, подкрепляя это решение качеством выпускаемого оборудования. А пока с учетом большого опыта работы мы открываем четыре сервисных центра в России Тюмени, Москве, Красноярске и Дзержинске.

\section{Есть ли в вашем арсенале уникальные изделия?}

А. Л. Пахомов: Да, например, отапливаемые боксы с оборудованием на винтовых сваях - полностью наша разработка, мы ведем также строительные работы по установке автономных блоков нашего оборудования. В Тюмени, в частности, работает 200 скважин, к обслуживанию которых мы приступим в самое ближайшее время, а наш сервис-центр обеспечит все необходимое для успешной работы оборудования как имеющихся скважин, так и тех, которые будут запущены в будущем.

\section{Каковы ваши предложения по повышению качества продукции, выпускаемой отечественными предприя- тиями?}

А. Л. Пахомов: Ориентир и руководство к действию в работе любого предприятия - нормативные документы. Они постоянно совершенствуются, но все равно на шаг отстают от требований сегодняшнего дня, что приводит к конфликтам между метрологами, аналитиками и контролирующими органами. Поэтому, мы считаем, что процесс валидации измерений на всех этапах производства является единственным решением для обеспечения наилучшего качества выпускаемой продукции. Еще одно наше предложение - финансовая ответственность поставщика оборудования. Если поставленное оборудование не обеспечивает требуемого качества, поставщика необходимо обязать за свой счет произвести его демонтаж и вывоз и заплатить штраф, покрывающий расходы по данному контракту. Тогда выиграет поставщик наиболее качественной продукции, впрочем, как и покупатель. Клиентам выгоднее заплатить на 10-15\% больше, но получить оборудование, не требующее дорогостоящего сервиса и обслуживания, постоянных трат на замену комплектующих, блоков и узлов, оплату работы

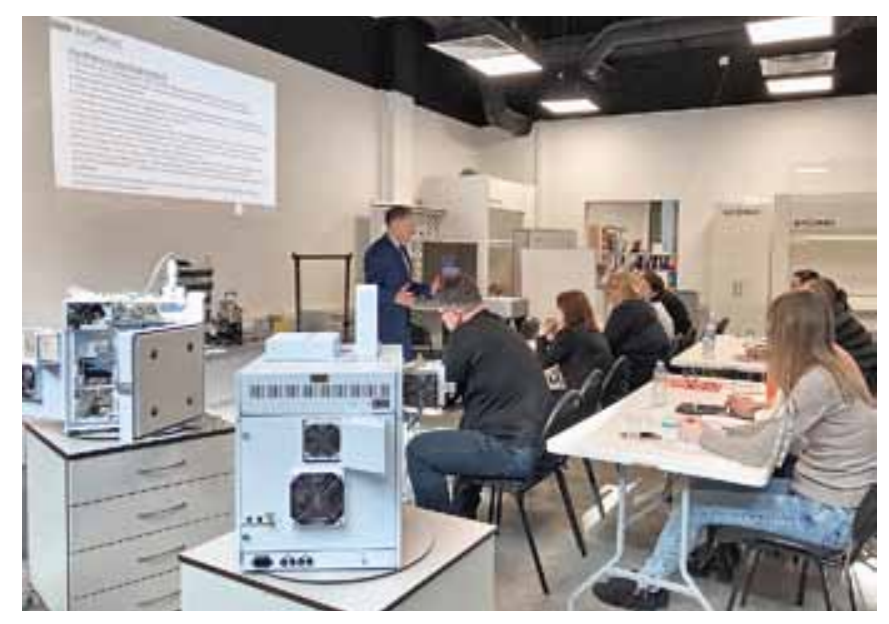

специалистов и командировочных пусконаладчиков. При поставке нашей продукции клиент получает за три первых года эксплуатации тройную прибыль. Наше предложение - контролировать расходы предприятий по позициям, связанным с конкретным оборудованием, материалами и ремонтом, в особенности, ЗИП. Это позволит выявить наиболее качественное оборудование и сэкономит значительные средства. Уже определено несколько заводов, где такой учет будет внедряться в качестве пилотного проекта. Затем этот опыт планируется распространить по всей территории Российской Федерации.

\section{Наме предложение - финансовая ответственность} поставщика оборудования

Добавлю, что создание сервис-центров только для лабораторных хроматографов не эффективно, слишком мала база лабораторий. Жизненно необходимы промышленные хроматографы, встроенные в процесс производства. За рубежом, по статистике, на 90 промышленных хроматографов приходится 10 лабораторных, а у нас наоборот. Долю промышленных анализаторов надо увеличивать, а лабораторный контроль - уменьшать. Понимание этого постепенно приходит к руководству предприятий, это еще один шаг к улучшению качества выпускаемой продукции, о чем мы неустанно говорим своим слушателям.

\section{Над чем вы сейчас работаете?}

А. л. Пахомов: Сейчас мы работаем над тремя модификациями потоковых хроматографов. Одна из них во взрывозащищенном исполнении по своим свойствам должна 
превзойти зарубежные аналоги. Наши ближайшие разработки должны привести к изменению методик аналитического контроля качества в отечественной промышленности, выпускаем новые детекторы, меняем нормативную документацию, разрабатываем новые методики, способствующие повышению качества продукции, выпускаемой отечественными предприятиями.

\section{Долю промышиенных}

\section{анализаторов}

\section{надо увеличивать, а пабораторный}

\section{контроль - уменьшать}

\section{Как работает ваша компания в условиях санкций и внедре-} ния национальной программы импортозамещения?

А. л. Пахомов: Наша задача в этом году - укрупнить производство. Мы создали ассоциацию инновационных проектов, чтобы довести их до практических результатов. Проводим выставки и контактируем с Индией, Ираном, Венесуэлой, Германией. На конференциях во Франкфуртена-Майне, в Питтсбурге мы убедились в том, что способны составить конкуренцию ведущим зарубежным производителям аналогичного оборудования. Рынок крупный, в разы больше отечественного, и его завоевание - теперь одна из

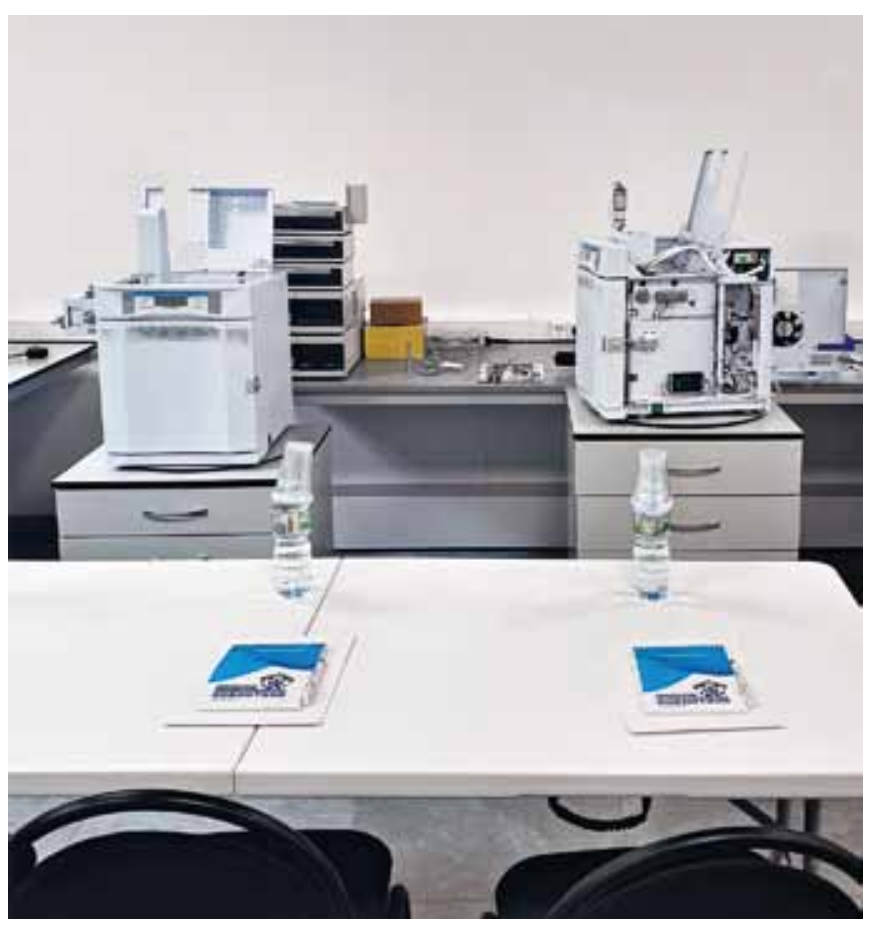

самых приоритетных задач, стоящих перед нашей компанией "Хромос Инжиниринг". Начать планируем с Канады, а потом развернуться там, где это возможно. Налаживаем связи с Киргизией, Узбекистаном, Азербайджаном, Казахстаном.

\section{Спасибо за интересный рассказ.}

СА. Л. Пахомовым и Е. А. Чудиным беседовапи О. А. Лаврентьева и А. Н. Алёшин

\section{КОМПЬЮТЕРНАЯ АКСИАЛЬНАЯ ЛИТОГРАФИЯ МАТЕРИАЛИЗУЕТ ПРЕДМЕТЫ}

3D-печать используют в производстве оптики, инструментов, микроструйных и медицинских устройств. Большинство методов 3D-печати основано на тех нологии послойного синтеза: гель или пластик наносят слой за слоем, формируя объект. Синтез этим способом занимает несколько часов, малопроизводителен и может вызвать анизотропию механических свойств объекта.

Китайские ученые разработали метод компьютерной аксиальной литографии для синтеза объектов произвольной геометрии с помощью

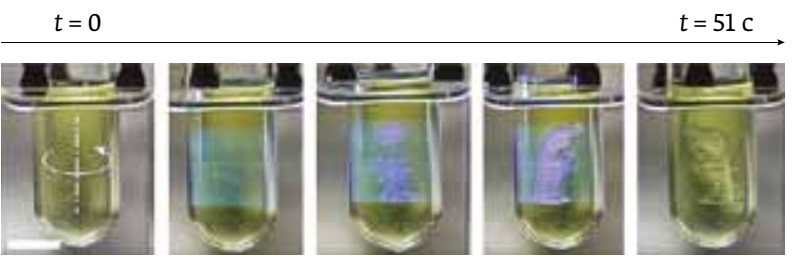

фотополимеризации в объеме. Цифровой проектор проецирует серию 2D-изображений предмета, снятых под разным углом, на вращающийся сосуд с фоточувствительным гелем. Фотоны пересекают гель и сталкиваются в заданных точках, суммарная энергия столкновений вызывает отвердевание геля. Фотоны, которые свободно проходят через гель, не меняют структуру материала. "Материализация» объекта размером в 2-3 см из геля занимает несколько минут. На создание технологии ученых вдохновил метод лучевой терапии с модулируемой интенсивностью - способ радиотерапии, в котором лучи радиации, направленные на тело пациента, создают 3D-образ с максимальной дозой облучения в области опухоли и минимально повреждают здоровые ткани.

Разработанным методом можно создавать сложные объекты, наращивать пластиковые части вокруг существующих объектов (ручка на железной отвертке), инкапсулировать чувствительные электронные детали.

Science, 2019. DOI: 10.1126/science.aau7114. 


\section{CHROMOS}

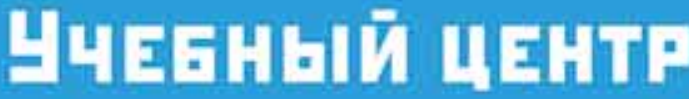

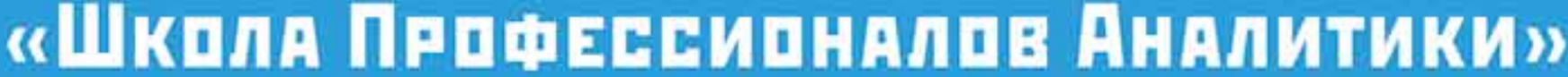 на базе ХРОМОС Инжиниринг}

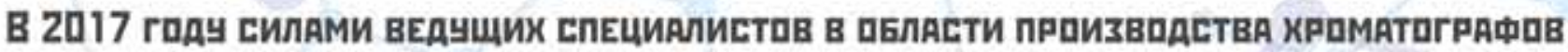

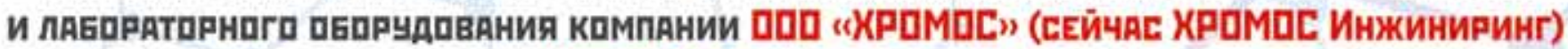

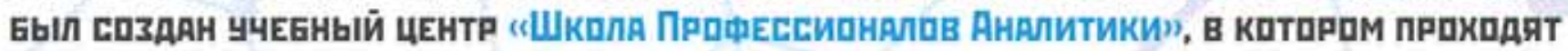
КЧРСЫ ПОВЫШЕНИЯ КВАЛИФИКАЦИИ ПО КРОМАТロГРА中ИИ.

Семинары проходят регулярно с периодичностью примерно раз в два месяца. Стандартный курс повышения квалификации занимает три рабочих дня (24 ч), число слушателей от 10 до 20 человек.

Мы учим обнаруживать неисправности и устранять их, отрабатываем базовый набор стандартных ситуаций, наиболее часто встречающихся при реальной работе с хроматографами.

В нашей Школе получить знания по хроматографии и повысить свою квалификацию в этой области могут люди разных направлений в работе и с разным уровнем знаний в области хроматографии. Среди наших обучающихся - сотрудники лабораторий, инженеры, специалисты КИПиА, начальники цЗЛ и руководители лабораторий, специалисты фирм - поставщиков лабораторного оборудования.

Программа обучения состоит как из аналитической части (освещаются теоретические вопросы по современным методам анализа в хроматографии), так и практической части, на которой обучающиеся могут своими руками собрать-разобрать хроматограф.

После окончания курса слушатели получают полный пакет учебных материалов в электронном виде. Всем, прошедшим обучение, выдается сертификат нашей Школы о прохождении курсов повышения квалификации в области хроматографии.

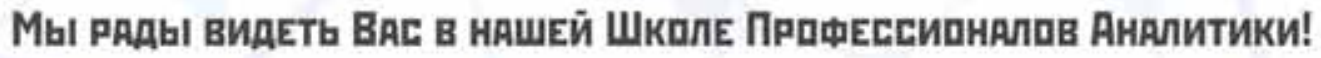

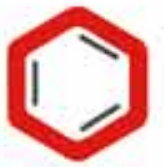

\section{Дата ближайшего семинара 21-23 мАя 2019 гадА}

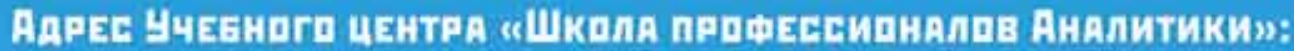

r. Mocква, БЦ Neo Geo, ул. Бутперова, А. 17, офис 3158

Тел, дия справок + 7 (499) 110-57-06; + $(968) 795-12-39$

Пouta: mailøproffimsknu

Сайт: www:шкопаaнапитики.pф 